\title{
The Effect of Synthesis Pressure on Properties of Eu-Doped ZnO Nanopowders Prepared by Microwave Hydrothermal Method
}

\author{
J. Rosowska ${ }^{a}$, J. KAszewski ${ }^{a, *}$, B. Witkowski ${ }^{a}$, Ł. WACHnicki $^{a}$ And M. Godlewski ${ }^{a, b}$ \\ ${ }^{a}$ Institute of Physics, Polish Academy of Sciences, Aleja Lotnikow 32/46, PL-02668 Warsaw, Poland \\ ${ }^{b}$ Dept. of Mathematics and Natural Sciences College of Science, Cardinal S. Wyszyński University, \\ Dewajtis 5, 01-815 Warsaw, Poland
}

\begin{abstract}
In the current research, europium doped $\mathrm{ZnO}$ nanopowders prepared by a microwave hydrothermal method are investigated. The effects of synthesis pressure on the morphologies, crystal structures, and optical properties of Eu-doped $\mathrm{ZnO}$ were analyzed by scanning electron microscopy, X-ray diffraction, cathodo- and photoluminescence. From our investigations it can be concluded that the synthesis pressure strongly influences the surface morphology. With the increase of the synthesis pressure from $2 \mathrm{MPa}$ to $10 \mathrm{MPa}$ significant changes can be observed. An increase of the mean crystallites sizes and change of the intensity ratio between the near band edge and defect related deep level emission band of $\mathrm{ZnO}$ were observed.
\end{abstract}

DOI: 10.12693/APhysPolA.130.1205

PACS/topics: 78.55.Hx, 81.07.Wx, 81.20.Ka, 78.60.Hk

\section{Introduction}

Nowadays, rare-earth (RE) doped II-VI semiconductors attract a lot of attention due to their wide potential applications in biology and medicine, including for example biological labels, biosensors, or drug delivery systems [1]. One of the most popular and suitable host material for $\mathrm{RE}$ doping is zinc oxide $\mathrm{ZnO}$. This semiconductor has a wide band gap $(3.37 \mathrm{eV})$ and high exciton binding energy $(60 \mathrm{MeV})$. An extensive use of $\mathrm{ZnO}$ originates also from its biocompatibility and nontoxicity. The $\mathrm{RE}$ ions are doped to $\mathrm{ZnO}$ to improve the luminescence efficiency [2]. Among them, $\mathrm{Eu}^{3+}$ ions have been investigated especially in view of their strong, sharp emission lines in red spectral region.

Many synthesis methods can be used to produce RE doped II-VI nanopowders. These techniques include for example sol-gel, hydrothermal synthesis, polyol, coprecipitation, combustion, gas-phase condensation [3-7]. Among them, the hydrothermal synthesis has been proven to be one of the most attractive and promising method [8]. First of all, this technique is non-expensive, relatively simple and easy to control [9]. Furthermore, it allows to obtain small nanoparticles with narrow distribution of sizes and high purity [10,11]. It is also known that synthesis conditions have a significant effect on the morphology and optical properties of the produced materials $[12,13]$. Optical, topographical and structural properties of $\mathrm{Eu}$ doped $\mathrm{ZnO}$ nanopowders obtained by hydrothermal method have been investigated earlier [14]. However, there is a lack of detailed studies on the effect of synthesis pressure on these features. Therefore, an attempt to resolve this issue became the main motivation for this work.

\footnotetext{
* corresponding author; e-mail: jaroslavuss@wp.pl
}

\section{Experimental details}

$\mathrm{ZnO}$ nanopowders doped with $0.5 \% \mathrm{~mol}$ of Eu were prepared by a microwave hydrothermal method using nitrate $(\mathrm{V})$ precursors. $18.187 \mathrm{~g}$ of zinc nitrate $(\mathrm{V})$ $\mathrm{Zn}\left(\mathrm{NO}_{3}\right)_{2} \cdot 6 \mathrm{H}_{2} \mathrm{O}$ (Sigma-Aldrich, Poland) and $0.131 \mathrm{~g}$ of europium(III) nitrate(V) $\mathrm{Eu}\left(\mathrm{NO}_{3}\right)_{3} \cdot 5 \mathrm{H}_{2} \mathrm{O}$ (SigmaAldrich, Poland) were dissolved in a distilled water. Then, the solution was stirred and alkalified with aqueous ammonia solution $(25 \%$, Carl Roth) to $\mathrm{pH}=10$. After obtaining a white precipitate, the product was washed repeatedly in distilled water and was moved to the Teflon reaction vessel of the microwave hydrothermal reactor (Ertec, Poland). Hydrothermal process was conducted at $2,4,6,8$ and $1 \mathrm{MPa}$ by $20 \mathrm{~min}$. After the syntheses, the samples were taken out and dried overnight at $40^{\circ} \mathrm{C}$. All Eu-doped $\mathrm{ZnO}$ nanopowders were prepared with the same procedure to study the pressure influence on properties of obtained samples.

$\mathrm{X}$-ray diffraction (XRD) measurements were carried out using Phillips XPert powder diffractometer working with $\mathrm{Cu} K_{\alpha}$ radiation $(1.54060 \AA)$. The data were taken for the $2 \theta$ range from $20^{\circ}$ to $70^{\circ}$ with a step of $0.05^{\circ}$. The surface morphology of the $\mathrm{Eu}$ doped $\mathrm{ZnO}$ nanopowders was examined by using scanning electron microscope (SEM) Hitachi model SU-70 with cathodoluminescence system GATAN Mono CL3. The add-on was necessary for optical investigations, which were conducted in the spectral range of 360-660 $\mathrm{nm}$. Photoluminescence (PL) and photoluminescence excitation (PLE) spectra were measured at room temperature with the Horiba/JobinYvon Fluorolog-3 spectrofluorimeter.

\section{Structural properties}

The XRD patterns of Eu doped samples obtained at different pressures are shown in Fig. 1. Diffraction patterns were divided into two ranges: normalized between $30-80^{\circ}$ and magnified $10 \times$ in range $15-30^{\circ}$. As seen in 


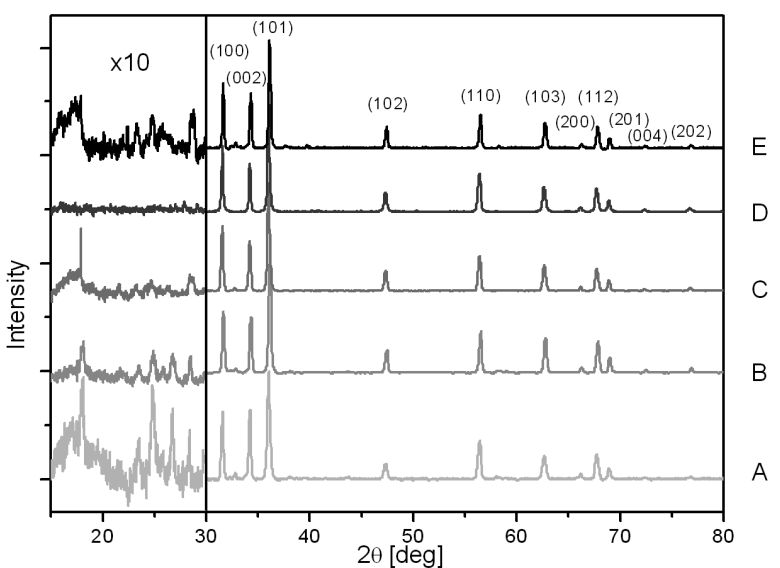

Fig. 1. X-ray diffraction patterns of $\mathrm{ZnO}: \mathrm{Eu}$ synthesized at the different pressures: $\mathrm{A}-2 \mathrm{MPa}$, $\mathrm{B}-4 \mathrm{MPa}, \mathrm{C}-6 \mathrm{MPa}, \mathrm{D}-8 \mathrm{MPa}, \mathrm{E}-10 \mathrm{MPa}$.

the figure, eleven Bragg reflections are observed, which can be indexed to wurtzite type $\mathrm{ZnO}$ structure (according to PDF card no. 36-1451). The Miller indices $(h k l)$ to each peak were assigned. We also conclude that majority of $\mathrm{Eu}^{3+}$ ions are doped into the $\mathrm{ZnO}$ lattice, since no diffraction peaks from europium related compounds were observed. The strongest diffraction peak originates from the preferred (101) orientation [15]. It is also worth noting that positions of main diffraction peaks of Eudoped $\mathrm{ZnO}$ samples are slightly shifted to lower angles compared to the diffraction patterns of undoped $\mathrm{ZnO}$. This fact can be explained by the difference between ionic radii of $\mathrm{Eu}^{3+}(0.95 \AA)$ and $\mathrm{Zn}^{2+}(0.74 \AA)$ [16]. The $\mathrm{Eu}^{3+}$ ions occupy the lattice sites of $\mathrm{Zn}^{2+}$ causing the increase in the inter-atomic distance and thus leading to the change in lattice parameters. A similar phenomenon was observed in other studies on Eu-doped $\mathrm{ZnO}$ structures [17, 18]. However, diffraction peaks from impurities are found in all the samples. These weak Bragg reflections are detected in the range of $2 \theta \approx 20-30^{\circ}$ and are assigned to zinc nitrate hydroxide family compounds exhibiting monoclinic structure [19]. The formulae of these compounds (followed by the powder diffraction file number) are: $\mathrm{Zn}_{5}\left(\mathrm{NO}_{3}\right)_{2}(\mathrm{OH})_{8} \cdot 2 \mathrm{H}_{2} \mathrm{O}$ (PDF card no. 24-1460), $\mathrm{Zn}_{3}(\mathrm{OH})_{4}\left(\mathrm{NO}_{3}\right)_{2}$ (PDF card no. 70-1361) and $\mathrm{Zn}(\mathrm{OH})\left(\mathrm{NO}_{3}\right) \cdot \mathrm{H}_{2} \mathrm{O}$ (PDF card no. 47-0965) [20]. Some reflexes of $\mathrm{Zn}_{5}\left(\mathrm{NO}_{3}\right)_{2}(\mathrm{OH})_{8} \cdot 2 \mathrm{H}_{2} \mathrm{O}$ phase are also seen at $2 \theta$ values of $33^{\circ}, 37^{\circ}, 39^{\circ}, 51^{\circ}$, and $58^{\circ}$. These impurities most likely crystallized from the remnants of the nitrate(V) groups, which were closed in the structure of the initial residue. Nanopowders contain different quantities of phase impurities, depending on the synthesis pressure. The relations between the impurity phases will not be discussed here in detail, since its content is relatively low.

In X-ray diffraction patterns, all the reflexes are broadened. It indicates small crystallite sizes as well as low crystallinity of obtained materials. The mean crystallite size (MCS) is estimated using the Scherrer formula (Fig. 2F). MCS values increase from 32 to $51 \mathrm{~nm}$ in the pressure range $2-10 \mathrm{MPa}$.

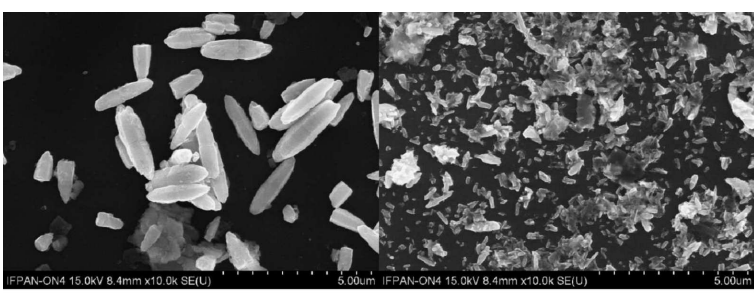

(A)

(B)

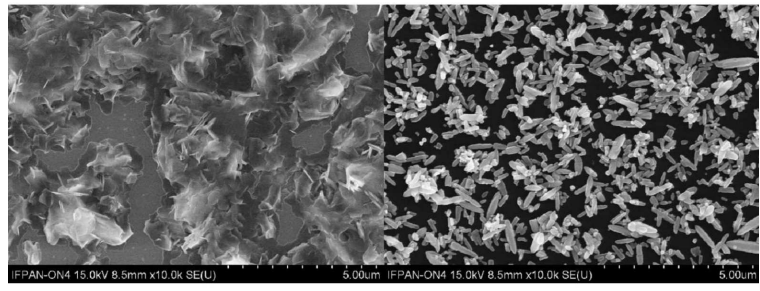

(C)

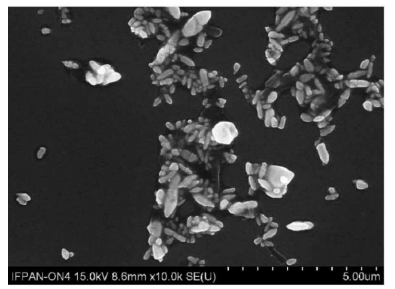

(E)
(D)

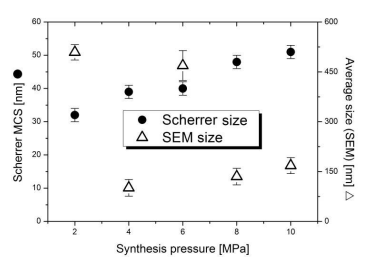

(F)
Fig. 2. Scanning electron microscopy (SEM) images of Eu-doped $\mathrm{ZnO}$ nanopowders obtained at the different pressures $\mathrm{A}-2 \mathrm{MPa}, \mathrm{B}-4 \mathrm{MPa}, \mathrm{C}-6 \mathrm{MPa}, \mathrm{D}-$ $8 \mathrm{MPa}, \mathrm{E}-10 \mathrm{MPa}, \mathrm{F}$ - Scherrer's size and SEM size as a function of pressure of synthesis.

Surface morphology was studied using SEM technique. The relevant results are shown in Fig. 2A-E. Generally, the morphology and the size of obtained nanopowders strongly depend on the pressure of the reaction. SEM images of Eu-doped $\mathrm{ZnO}$ nanopowders indicate that samples prepared at the different pressures vary in shape and size. As presented in Fig. 2A, 2D, 2E grains obtained at the pressure of 2,8 , and $10 \mathrm{MPa}$ are elongated, similar to deformed hexagonal prisms. On the other hand, additional irregular nanoplate-like structures were observed in Fig. $2 \mathrm{C}$ as well as in $2 \mathrm{~B}$ with additional elongated hexagonal prisms. The average grain/agglomerate sizes were directly taken from the SEM images (Fig. 2F). At least 500 of the objects were measured for each pressure. In the case of elongated, hexagonal prism shaped $\mathrm{ZnO}$ grains, transverse size was measured along (101) and (100) planes. Preferred growth axis is, however, (002) as indicate the longest sides of the prisms.

It is worth noting that the size of grains in the samples obtained directly from the SEM images is larger than that derived from the XRD data (Fig. 2F). This means that the SEM images do not show the primary ZnO crystallites, but rather display the size of agglomerates.

\section{Spectroscopic properties}

PL emission spectra were measured with excitation wavelength $260 \mathrm{~nm}$ at room temperature. The PL data is 
shown in Fig. 3. The spectra of obtained samples consist of two emission bands. One of them is peaking around $392 \mathrm{~nm}$ (UV) and is related to near band excitonic emission (NBE) [21]. The broad band emission from 450 to $700 \mathrm{~nm}$ is named deep level emission (DLE) and is attributed to intrinsic defects in the crystal structure, such as O-vacancy, O-interstitial, Zn-vacancy, Zn-interstitial, O-antisite and extrinsic impurities [22]. The near band edge emission is weakly visible in the sample prepared at $2 \mathrm{MPa}$ (Fig. 3A) suggesting a low crystallinity of the material. This corresponds with MCS calculations. In all cases, no emission related to $\mathrm{Eu}^{3+}$ was observed, because the excitation wavelength is lower than $385 \mathrm{~nm} \mathrm{[23]} \mathrm{and}$ the $4.7 \mathrm{eV}(260 \mathrm{~nm})$ photons are not in resonance with any transitions of $\mathrm{Eu}^{3+}$ ions. It is also worth noting that the intensity ratio of $I_{\mathrm{NBE}}$ to $I_{\mathrm{DLE}}$ is increasing with the synthesis pressure, as seen in Fig. 3B. The ratio of near band edge and deep level emission was calculated by integrating the spectra in the ranges $300-420 \mathrm{~nm}$ and 420-800 nm for each type of luminescence respectively and division of resulting values (Fig. 3B). The ratio for both CL (spectra not shown) and PL measurements increases, suggesting improvement of material crystallinity with increasing synthesis pressure.
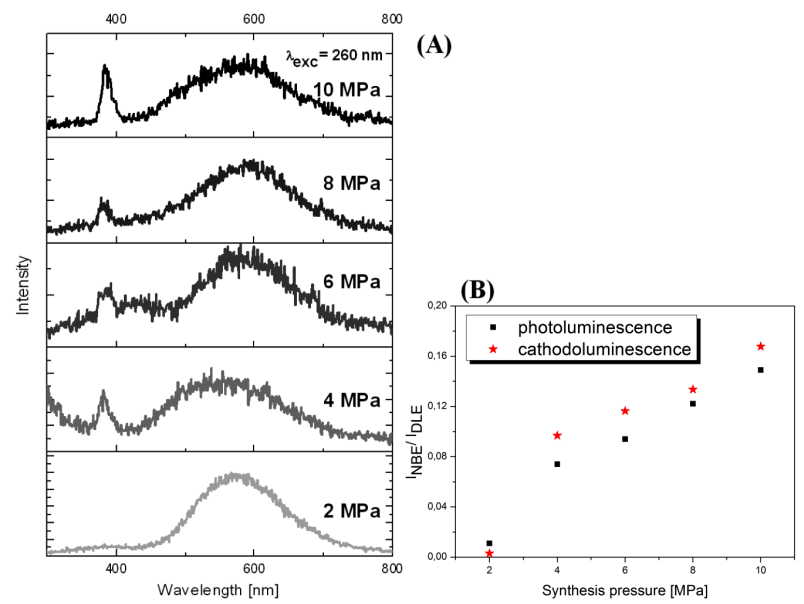

Fig. 3. A - normalized photoluminescence emission spectra excited at $260 \mathrm{~nm}$ of nanopowders obtained at the different pressures. $\mathrm{B}$ - the intensity ratio of $I_{\mathrm{NBE}}$ to $I_{\mathrm{DLE}}$ versus synthesis pressure obtained for CL and PL measurements.

Photoluminescence emission spectra, which were taken with the resolution of $0.2 \mathrm{~nm}$ and for excitation wavelength $\lambda_{\text {exc }}=466 \mathrm{~nm}$, are depicted in Fig. 4. Sharp emission lines, which are derived from ${ }^{5} D_{0} \rightarrow{ }^{7} F_{J}(J=0-4)$ family are well seen in the spectra $\mathrm{C}$ and $\mathrm{D}$. The point group of $\mathrm{Eu}^{3+}$ ions can be deduced. It is possible because $\mathrm{Eu}^{3+}$ ion has non-degenerate ground state ${ }^{7} F_{0}$ and well-separated, non-overlapping ${ }^{2 S+1} L_{j}$ multiplets [24]. The site symmetry of $\mathrm{Eu}^{3+}$ ion can be found on the basis of the number of the spectral lines in the PL spectrum for excitation wavelength $466 \mathrm{~nm}$. For transition ${ }^{5} D_{0} \rightarrow{ }^{7} F_{0}$ only one, weak peak is observed. Emission lines related to the magnetic dipole transitions ${ }^{5} D_{0} \rightarrow^{7} F_{1}$ consist of two peaks. It is known that the intensity of those lines significantly varies with the local environment of $\mathrm{Eu}^{3+}$ ions [25]. The electric dipole ${ }^{5} D_{0} \rightarrow^{7} F_{2}$ transitions lines are the most intensive and show three peaks, where the third one can be detected as a shoulder of the second peak. This transition is very sensitive to coordination environment of $\mathrm{Eu}^{3+}$ ions [26], so the intensities of ${ }^{5} D_{0} \rightarrow{ }^{7} F_{2}$ and ${ }^{5} D_{0} \rightarrow{ }^{7} F_{1}$ can be a measure of distortion and deviation from site symmetries of $\mathrm{Eu}^{3+}$. Taking all this into account, in the case of samples obtained at 6 and $8 \mathrm{MPa}$, trivalent europium ions are substituting zinc in $\mathrm{ZnO}$ lattice and are located at a site with $C_{3 v}$ symmetry.

In the spectra of samples obtained at 2, 4, and $10 \mathrm{MPa}$ (Fig. 4A,B,E) photoluminescence peaks overlap. In a large extent the broad lines cover the crystal field splitting structure and in this case is not possible to make a symmetry determination. The inhomogeneous line broadening indicates that there are many non-equivalent sites in the crystal lattice [24].

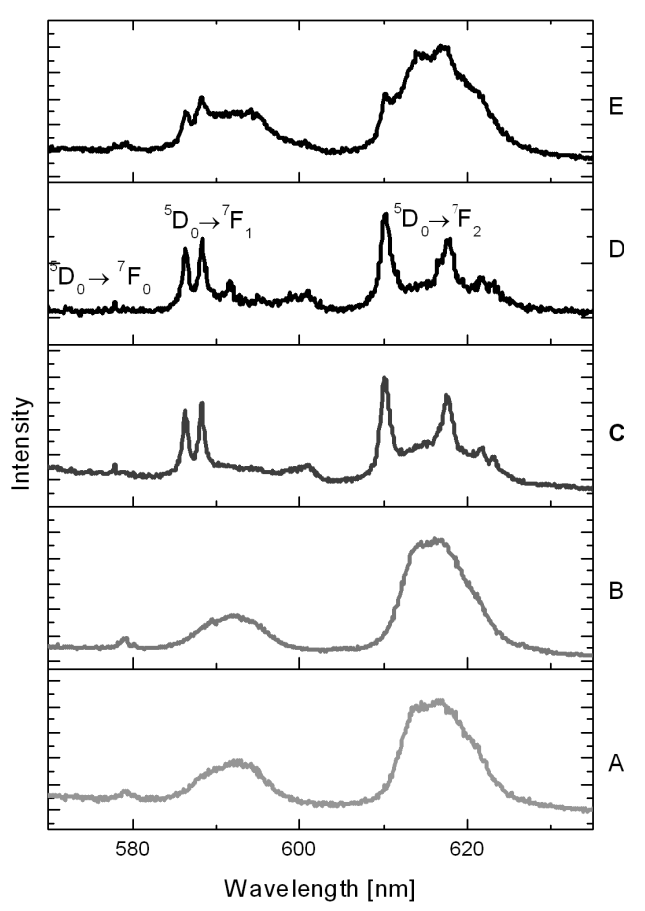

Fig. 4. Normalized photoluminescence emission spectra $\left(\lambda_{\text {exc }}=466 \mathrm{~nm}\right)$ of nanopowders obtained at the different pressures: $\mathrm{A}-2 \mathrm{MPa}, \mathrm{B}-4 \mathrm{MPa}, \mathrm{C}-$ $6 \mathrm{MPa}, \mathrm{D}-8 \mathrm{MPa}, \mathrm{E}-10 \mathrm{MPa}$.

Figure 5 compares photoluminescence excitation spectra for the $613 \mathrm{~nm}$ emission (major $\mathrm{Eu}^{3+}$ emission peak) obtained for samples prepared at different synthesis pressures. Sharp emission lines attributed to ${ }^{7} F_{0} \rightarrow{ }^{5} L_{6}$ (at $396 \mathrm{~nm}$ ) and ${ }^{7} F_{0} \rightarrow{ }^{5} D_{2}$ (at $466 \mathrm{~nm}$ ) transitions are observed in all the spectra, but the weak peak related to ${ }^{7} F_{0} \rightarrow{ }^{5} D_{3}$ (at $416 \mathrm{~nm}$ ) is not detected in sample produced at the lowest synthesis pressure (Fig. 5A). 
Sharp lines of this spectrum are not intensive and wellseparated, which might suggest a distortion of lattice environment.

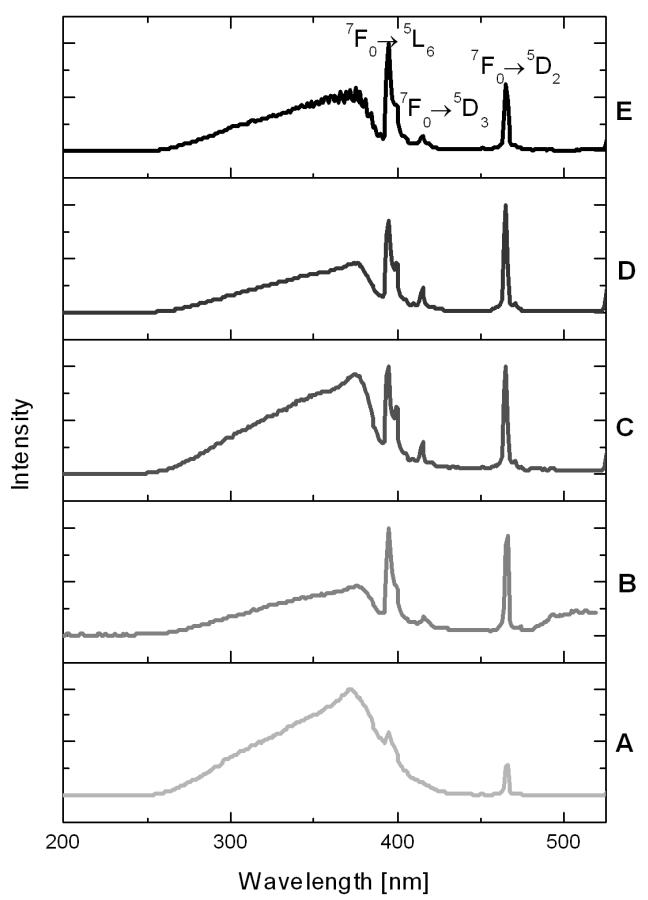

Fig. 5. Photoluminescence excitation spectra of samples obtained at the different pressures: $\mathrm{A}-2 \mathrm{MPa}$, $\mathrm{B}-4 \mathrm{MPa}, \mathrm{C}-6 \mathrm{MPa}, \mathrm{D}-8 \mathrm{MPa}, \mathrm{E}-10 \mathrm{MPa}$.

\section{Conclusions}

The effect of synthesis pressure on properties of Eudoped $\mathrm{ZnO}$ nanopowders prepared by microwave hydrothermal method was investigated. Various morphologies of Eu-doped $\mathrm{ZnO}$ nanopowders were obtained from different reaction pressures. From the SEM investigations can be found that the synthesis pressure can change the surface morphology of $\mathrm{Eu}$ doped $\mathrm{ZnO}$ nanopowders. From XRD investigations, diffraction peaks from impurities were detected. The lowest content of hydroxide nitrate phases was observed in $8 \mathrm{MPa}$ sample. Results of PL and PLE measurements indicate that the samples prepared at 2 and $4 \mathrm{MPa}$ show the lowest crystallinity. The intensity ratio between the band edge and defect related band of $\mathrm{ZnO}$ is increased with the synthesis pressure as well as the mean crystallite sizes. Generally, the results revealed improvement in crystal structure with increase of synthesis pressure.

\section{References}

[1] E. Wolska, B.S. Witkowski, M. Godlewski, Acta Phys. Pol. A 119, 683 (2011).

[2] M. Godlewski, E. Wolska, S. Yatsunenko, A. Opalińska, J. Fidelus, W. Łojkowski, M. Zalewska, A. Kłonkowski, D. Kuritsyn, Low Temp. Phys. 35, 48 (2009).
[3] W. Strek, E. Zych, D. Hreniak, J. Alloys Comp. 344, $332(2002)$.

[4] W. Zawadzki, J. Wrzyszcz, W. Strek, D. Hreniak, J. Alloys Comp. 323/324, 279 (2001).

[5] Y.R. Wang, K.Q. Lu, D.H. Wang, Z.H. Wu, Z.Z. Fang, J. Phys. Condens. Matter 6, 633 (1994).

[6] E. Zych, D. Hreniak, W. Strek, J. Phys. Chem. B 106, 3805 (2002).

[7] D.K. Williams, H. Yuan, B.M. Tissue, J. Lumin. 83/84, 297 (1999).

[8] K. Byrappa, T. Adschiri, Progr. Cryst. Growth Character. Mater. 53, 117 (2007).

[9] S. Somiya, T. Akiba, J. Eur. Ceram. Soc. 19, 81 (1999).

[10] T. Wejrzanowski, R. Pielaszek, A. Opalińska, H. Matysiak, W. Łojkowski, K.J. Kurzydłowski, Appl. Surf. Sci. 253, 204 (2006).

[11] S. Yatsunenko, J. Kaszewski, J. Grzyb, I. Pełech, M.M. Godlewski, E. Mijowska, U. Narkiewicz, M. Godlewski, J. Phys. Condens. Matter 25, 194106 (2013).

[12] A. Opalińska, C. Leonelli, W. Łojkowski, R. Pielaszek, E. Grzanka, T. Chudoba, H. Matysiak, T. Wejrzanowski, K.J. Kurzydłowski, J. Nanomater. 1, 98769 (2006).

[13] J. Kaszewski, S. Yatsunenko, I. Pełech, E. Mijowska, U. Narkiewicz, M. Godlewski, Pol. J. Chem. Technol. 16, 99 (2014)

[14] E. Wolska, J. Kaszewski, P. Kiełbik, J. Grzyb, M.M. Godlewski, M. Godlewski, Opt. Mater. $\mathbf{3 6}$, 1655 (2014).

[15] Y.K. Mishra, S. Mohapatra, R. Singhal, D.K. Avasthi, D.C. Agarwal, S.B. Ogale, Appl. Phys. Lett. 92 , 103105 (2008).

[16] R.D. Shannon, Acta Crystallogr. A 32, 751 (1976).

[17] Vinod Kumar, Vijay Kumar, S. Som, M.M. Duvenhage, O.M. Ntwaeaborwa, H.C. Swart, Appl. Surf. Sci. 308, 419 (2014).

[18] M. Wang, Ch. Huang, Z. Huang, W. Guo, J. Huang, H. He, H. Wang, Y. Cao, Q. Liu, J. Liang, Opt. Mater. 31, 1502 (2009).

[19] W. Stählin, H.R. Oswald, Acta Crystallogr. B 26 , 860 (1970).

[20] S.J. Ahmadi, M. Hosseinpour, F. Javadi, R. Tayebee, Industr. Eng. Chem. Res. 52, 1448 (2013).

[21] A.K. Singh, V. Viswanath, C. Janu, J. Lumin. 129, 874 (2009).

[22] M. Najafi, H. Haratizadeh, Solid State Sci. 41, 48 (2015).

[23] Y.K. Park, J.I. Han, M.G. Kwak, H. Yang, S.H. Ju, W.S. Cho, Appl. Phys. Lett. 72, 668 (1998).

[24] K. Binnemans, C. Görller-Walrand, J. Rare Earths 14, 173 (1996).

[25] L. Yang, Z. Jiang, J. Dong, A. Pan, X. Zhuang, Mater. Lett. 129, 65 (2014)

[26] H. Shahroosvand, M. Ghorbani-asl, J. Lumin. 144 223 (2013). 